Article

\title{
Single Crystal Elastic Properties of Hemimorphite, a Novel Hydrous Silicate
}

\author{
Yingzhe Li and Jay D. Bass * \\ Geology Department, University of Illinois, Urbana, IL 61801, USA; yli200@illinois.edu \\ * Correspondence: jaybass@illinois.edu; Tel.: +1-217-333-1018
}

Received: 6 April 2020; Accepted: 7 May 2020; Published: 10 May 2020

check for updates

\begin{abstract}
Hemimorphite, with the chemical formula $\mathrm{Zn}_{4} \mathrm{Si}_{2} \mathrm{O}_{7}(\mathrm{OH})_{2} \cdot \mathrm{H}_{2} \mathrm{O}$, contains two different types of structurally bound hydrogen: molecular water and hydroxyl. The elastic properties of single-crystal hemimorphite have been determined by Brillouin spectroscopy at ambient conditions, yielding tight constraints on all nine single-crystal elastic moduli $\left(\mathrm{C}_{\mathrm{ij}}\right)$. The Voigt-Reuss-Hill (VRH) averaged isotropic aggregate elastic moduli are $\mathrm{K}_{\mathrm{S}}(\mathrm{VRH})=74(3) \mathrm{GPa}$ and $\mu(\mathrm{VRH})=27(2) \mathrm{GPa}$, for the adiabatic bulk modulus and shear modulus, respectively. The average of the Hashin-Shtrickman (HS) bounds are Ks (HS) = 74.2(7) GPa and and $\mu(\mathrm{HS})=26.5(6) \mathrm{GPa}$. Hemimorphite displays a high degree of velocity anisotropy. As a result, differences between upper and lower bounds on aggregate properties are large and the main source of uncertainty in Ks and $\mu$. The HS average $\mathrm{P}$ wave velocity is $V_{P}=5.61(4) \mathrm{km} / \mathrm{s}$, and the HS S-wave velocity is $V_{S}=2.77(3) \mathrm{km} / \mathrm{s}$. The high degree of elastic anisotropy among the on-diagonal longitudinal and pure shear moduli of hemimorphite are largely explained by its distinctive crystal structure.
\end{abstract}

Keywords: elastic properties; Brillouin; hydrogen bonds; sound velocity

\section{Introduction}

The influence of hydrogen, or "water", on the elastic properties of minerals is a topic of great current interest for possibly identifying hydrous phases in the deep crust and mantle from seismic models for these regions. Adding hydrogen bonds into crystal structures is widely assumed to decrease the density, and elastic moduli of silicate minerals by increasing their volume, at least at ambient conditions. However, the effect of water on the elastic properties of minerals can depend greatly on details of the crystal structure into which hydrogen is incorporated, and on whether hydrogen is present in the form of hydroxyl $\mathrm{OH}^{-}$or as molecular water. Hydration of wadsleyite, ringwoodite and garnet can change elastic moduli significantly [1,2], in contrast to the olivine-chondrodite group [3], which varies less, with a similar water content. These differences are considered to be caused by different incorporation mechanisms of hydrogen into their structures. To investigate the influence of water on the direction-dependent compressibility, or elastic anisotropy, of minerals, it is necessary to measure the single-crystal elastic moduli matrix, $\mathrm{C}_{\mathrm{ij}}$. Hemimorphite, $\mathrm{Zn}_{4} \mathrm{Si}_{2} \mathrm{O}_{7}(\mathrm{OH})_{2} \cdot \mathrm{H}_{2} \mathrm{O}$, a hydrated alteration product of willemite, $\mathrm{Zn}_{2} \mathrm{SiO}_{4}$, is interesting, in that it contains both molecular $\mathrm{H}_{2} \mathrm{O}$ and $\mathrm{OH}^{-}$hydroxyl bonded into its structure. In nature hemimorphite is an economic ore mineral in supergene non-sulfide zinc deposits. Some significant deposits are dominated by hemimorphite, such as Shaimerden supergene deposit in Kazakhstan, the Cho Dien district in Vietnam, and the Skorpion deposit in Namibia [4].

The content of structurally bound $\mathrm{H}_{2} \mathrm{O}$ of hemimorphite is $7.18 \mathrm{wt} \%$ [5]. It has two phase transitions below room temperature related to ordered versus dynamically disordered $\mathrm{H}_{2} \mathrm{O}$ and $\mathrm{OH}^{-}$ in the crystal structure at 20 and $90 \mathrm{~K}$, respectively [6]. At elevated temperatures, hemimorphite dehydrates in two stages. It loses molecular $\mathrm{H}_{2} \mathrm{O}$ without breakdown of the structure at $550{ }^{\circ} \mathrm{C}$, then 
undergoes a phase transition to $\beta-\mathrm{Zn}_{2} \mathrm{SiO}_{4}$, involving release of the $\mathrm{OH}^{-}$group between $725-760{ }^{\circ} \mathrm{C}$. If heated above $960^{\circ} \mathrm{C}$, it transforms into willemite $\left(\alpha-\mathrm{Zn}_{2} \mathrm{SiO}_{4}\right)$ [7].

The structure of orthorhombic hemimorphite, with space group Imm2, is composed of a three-dimensional framework, in which two $\mathrm{ZnO}_{3}(\mathrm{OH})$ tetrahedra and one $\mathrm{SiO}_{4}$ tetrahedron form three-membered rings that are corner-shared to form corrugated sheets parallel to (010) [8,9] (Figure 1). $\mathrm{SiO}_{4}$ tetrahedra in one layer are linked to $\mathrm{SiO}_{4}$ tetrahedra in an adjacent layer, while the $\mathrm{ZnO} 3(\mathrm{OH})$ tetrahedra in adjacent layers also only link to each other, completing the framework. Large open channels run parallel to [001], giving hemimorphite a structural similarity to zeolites. The molecular water, orientated in the (010) plane, is near the center of large cavities of an eight-membered ring and bonded to hydroxyl groups of the $\mathrm{ZnO}_{3}(\mathrm{OH})$ tetrahedra by hydrogen bonds. The hydrogen bonds formed by $\mathrm{H}$ of hydroxyl group (H35) are stronger than those formed by H of molecular water (H53) [8]. The presence of both hydroxyl and molecular water, corrugated sheets in a tetrahedral framework, and large zeolitic cavities, make hemimorphite a rather novel silicate mineral. The objective of this project was to measure the elastic properties of hemimorphite, in order to investigate its structure-property relations, and as a first step toward understanding how $\mathrm{H}_{2} \mathrm{O}$ and $\mathrm{OH}^{-}$influence sound velocities and elasticity.

(a)

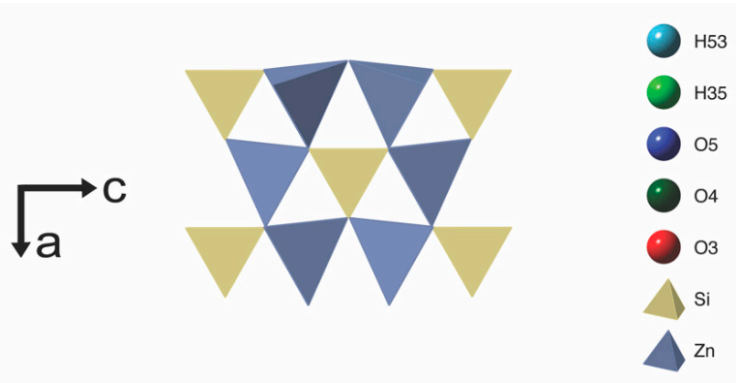

(b)

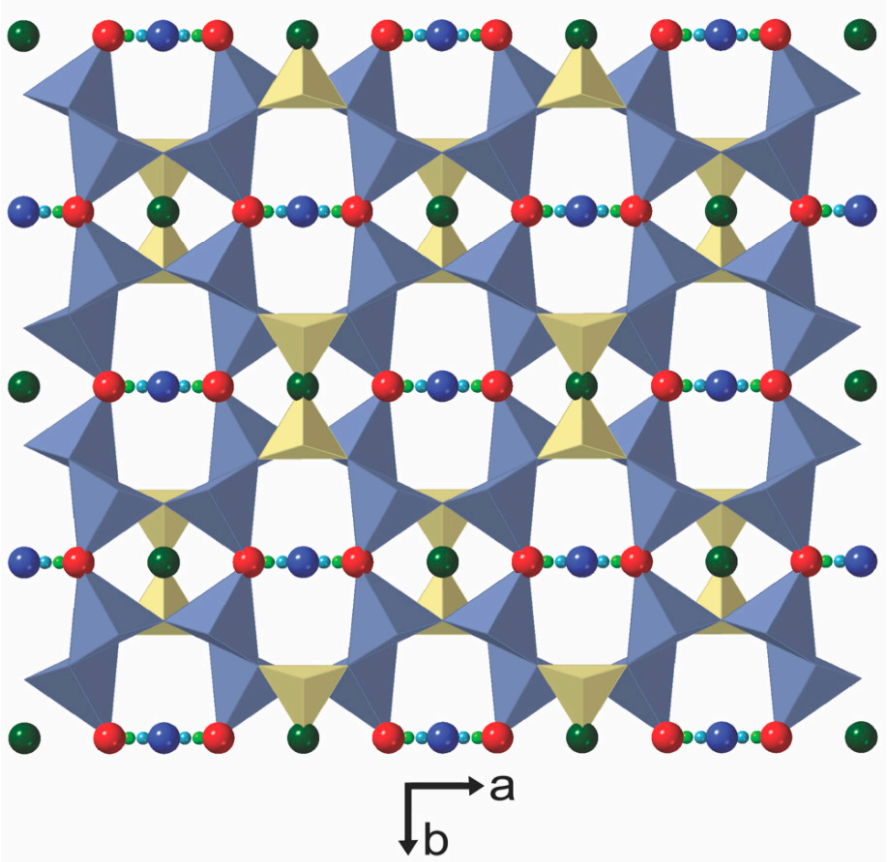

Figure 1. The crystal structure of hemimorphite. (a) Here, two zinc and one silicon tetrahedra comprise three-membered ring in (010) plane; (b) the structure of hemimorphite projected onto the $\mathrm{a}-\mathrm{b}$ plane. Six-membered rings and eight-membered rings are in the $\mathrm{a}-\mathrm{b}$ plane. Large cavities run along the $\mathrm{c}$ axis and contain $\mathrm{H}_{2} \mathrm{O}$. The corrugated layers of three-membered rings are also apparent in this projection (modified from Hill, et al., 1977 [8]). 


\section{Materials and Methods}

Our samples of hemimorphite are from the Mapimí mine, Durango, Mexico. The sample contains a "spray" of transparent euhedral crystals with clearly defined faces. Most crystals exhibit tabular planes parallel to (010), and striations parallel to [001]. From single-crystal X-ray diffraction using a four-circle diffractometer, the average lattice parameters obtained on three single crystals are: $\mathrm{a}=$ 8.37(2) $\AA, b=10.722(4) \AA$, and $c=5.118(7) \AA$, with unit cell volume $V_{0}=459(1) \AA^{3}$. The lattice parameters are consistent with the values reported in earlier crystal structure determinations by Hill et al. [8], McDonald and Cruickshank [9], Takeuchi et al. [10] and Cooper and Gibbs [11].

Scanning electron microscopy-energy dispersive spectroscopy (SEM-EDS) was used to obtain the major element chemical composition of hemimorphite. The results show that our samples are iron-free, nearly pure zinc silicates. The calculated density $\rho=3.48(3) \mathrm{g} / \mathrm{cm}^{3}$ was derived from the chemical formula $\mathrm{Zn}_{4} \mathrm{Si}_{2} \mathrm{O}_{7}(\mathrm{OH})_{2} \cdot \mathrm{H}_{2} \mathrm{O}$ with $\mathrm{Z}=2$ and the unit cell volume given by $X$-ray diffraction.

Three near-principal sections of hemimorphite were polished with parallel faces in the $a-b, b-c$, and a-c crystallographic planes. The orientations of the polished surfaces were obtained by specular goniometry measurements and the X-ray orientation matrices for each crystal. The accuracy of sample orientation was within 0.5 degrees. For the Brillouin scattering measurements, a single-frequency diode pumped solid-state laser of wavelength $532 \mathrm{~nm}$ was used as a light source. All measurements were performed using a $90^{\circ}$ platelet symmetric scattering geometry [12] at ambient conditions. The scattered light was analyzed by a piezoelectrically-scanned tandem Fabry-Perot interferometer [13].

For each principal section, acoustic velocities were determined in 26 distinct crystallographic directions by changing the chi angle on the three-circle Eulerian cradle in 15 degrees increments. Measurements were made in a total of 78 distinct crystallographic directions, yielding 156 acoustic mode velocities (78 longitudinal and 78 single shear modes).

\section{Results}

From the measured Brillouin frequency shifts, $\Delta v_{B}$, velocity $\mathrm{v}$ in a given crystallographic direction $\mathrm{i}$ is derived from the equation for symmetric platelet geometry [12]:

$$
\mathrm{v}_{\mathrm{i}}=\frac{\lambda_{0} \Delta v_{\mathrm{B}}}{2 \sin \frac{\Theta}{2}}
$$

where $\lambda_{0}$ is the wavelength of the incident laser light, and $\theta$ is the external angel between the incident and scattered light.

The single-crystal elastic moduli tensor of orthorhombic hemimorphite contains nine independent non-zero elastic moduli $C_{\mathrm{ij}}$. On-diagonal moduli were well constrained by the acoustic velocities in the directions very close to the crystallographic axes. A linearized inversion method of Weidner and Carleton [14], was used to obtain a least-squares best-fit model of the elastic moduli $C_{\mathrm{ij}}$ derived from the velocities. Figure 2 and Table 1 show a comparison between model and observed data of phonon velocities. The root-mean-square (RMS) residual in velocity for the final best-fit $\mathrm{C}_{\mathrm{ij}}$ model is $32.4 \mathrm{~m} / \mathrm{s}$. Hemimorphite exhibits considerable longitudinal and shear velocity anisotropy (Figure 2 and Table 2). 


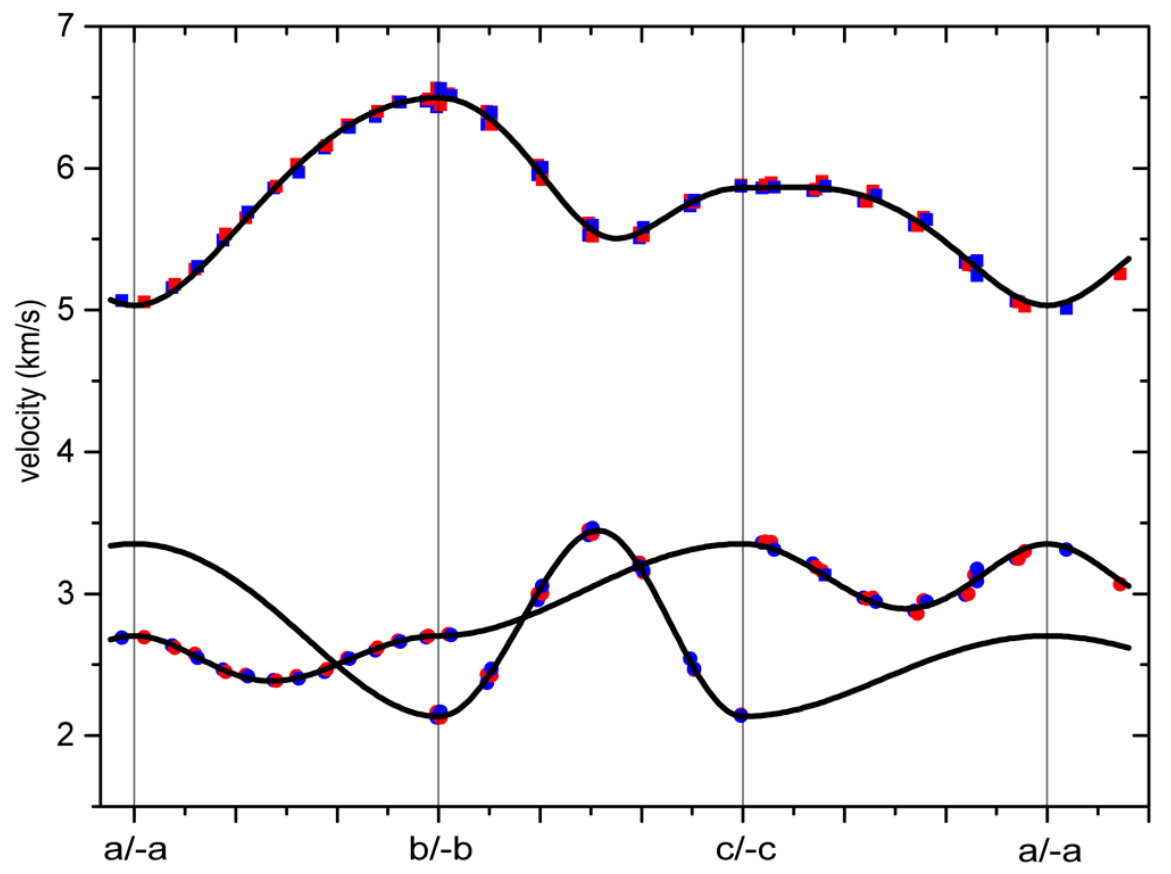

Figure 2. Measured acoustic velocities of hemimorphite (solid symbols), as a function of crystallographic directions projected onto the $\mathrm{a}-\mathrm{b}, \mathrm{b}-\mathrm{c}$, and $\mathrm{a}-\mathrm{c}$ crystallographic planes. Squares and circles represent $V_{P}$ and Vs measurements, respectively. The red symbols are measured on (001), (100) and (010); blue symbols are measured on the $(00 \overline{1}),(00)$ and $(010)$. The best-fit acoustic velocity model is shown by solid lines. Error bars are smaller than the size of symbols.

Table 1. Acoustic measurements of hemimorphite at ambient conditions.

\begin{tabular}{ccccccccc}
\hline \multicolumn{2}{c}{ Phonon Direction Cosines } & \multicolumn{3}{c}{$\mathbf{V}_{\mathbf{P}}(\mathbf{m} / \mathbf{s})$} & \multicolumn{3}{c}{$\mathbf{V}_{\mathbf{S}}(\mathbf{m} / \mathbf{s})$} \\
\hline $\mathbf{n}_{\mathbf{a}}$ & $\mathbf{n}_{\mathbf{b}}$ & $\mathbf{n}_{\mathbf{c}}$ & Obs. & Model & Residual & Obs. & Model & Residual \\
\hline 0.936 & -0.005 & -0.352 & 5314 & 5293 & 21 & 3130 & 3110 & 20 \\
0.812 & -0.009 & -0.583 & 5654 & 5580 & 73 & 2951 & 2916 & 35 \\
0.632 & -0.013 & -0.775 & 5837 & 5777 & 60 & 2971 & 2935 & 36 \\
0.409 & -0.016 & -0.912 & 5906 & 5858 & 48 & 3159 & 3126 & 33 \\
0.159 & -0.016 & -0.987 & 5897 & 5865 & 33 & 3362 & 3314 & 48 \\
-0.102 & -0.012 & -0.995 & 5881 & 5863 & 18 & 3367 & 3337 & 31 \\
-0.355 & -0.004 & -0.935 & 5851 & 5864 & -12 & 3188 & 3176 & 12 \\
-0.584 & 0.006 & -0.812 & 5764 & 5806 & -42 & 2964 & 2969 & -5 \\
-0.773 & 0.016 & -0.634 & 5594 & 5640 & -46 & 2861 & 2900 & -39 \\
-0.91 & 0.024 & -0.414 & 5318 & 5371 & -53 & 2998 & 3048 & -50 \\
-0.986 & 0.028 & -0.167 & 5057 & 5103 & -47 & 3246 & 3286 & -40 \\
-0.995 & 0.027 & 0.092 & 5027 & 5057 & -31 & 3299 & 3331 & -31 \\
-0.938 & 0.021 & 0.345 & 5253 & 5286 & -33 & 3066 & 3118 & -52 \\
-0.942 & 0.001 & 0.336 & 5241 & 5275 & -34 & 3089 & 3126 & -37 \\
-0.997 & 0.000 & 0.083 & 5011 & 5051 & -40 & 3312 & 3335 & -23 \\
-0.985 & 0.003 & -0.176 & 5063 & 5109 & -46 & 3248 & 3279 & -31 \\
-0.906 & 0.008 & -0.423 & 5334 & 5381 & -47 & 2991 & 3038 & -48 \\
-0.767 & 0.015 & -0.641 & 5596 & 5647 & -51 & 2878 & 2898 & -20 \\
-0.576 & 0.022 & -0.817 & 5766 & 5809 & -43 & 2972 & 2975 & -3 \\
-0.346 & 0.027 & -0.938 & 5840 & 5863 & -24 & 3212 & 3183 & 28 \\
-0.092 & 0.027 & -0.995 & 5859 & 5862 & -3 & 3361 & 3339 & 22 \\
0.169 & 0.023 & -0.985 & 5867 & 5864 & 4 & 3312 & 3309 & 4 \\
0.418 & 0.014 & -0.908 & 5873 & 5857 & 16 & 3133 & 3118 & 15 \\
0.64 & 0.003 & -0.769 & 5811 & 5773 & 38 & 2944 & 2930 & 14 \\
\hline
\end{tabular}


Table 1. Cont.

\begin{tabular}{|c|c|c|c|c|c|c|c|c|}
\hline \multicolumn{3}{|c|}{ Phonon Direction Cosines } & \multicolumn{3}{|c|}{$V_{P}(m / s)$} & \multicolumn{3}{|c|}{$\mathrm{V}_{\mathrm{S}}(\mathrm{m} / \mathrm{s})$} \\
\hline $\mathbf{n}_{\mathbf{a}}$ & $\mathbf{n}_{\mathbf{b}}$ & $\mathbf{n}_{\mathrm{c}}$ & Obs. & Model & Residual & Obs. & Model & Residual \\
\hline 0.817 & -0.008 & -0.576 & 5637 & 5571 & 65 & 2943 & 2920 & 24 \\
\hline 0.939 & -0.018 & -0.343 & 5348 & 5283 & 64 & 3175 & 3120 & 55 \\
\hline 0.004 & -1.000 & 0.003 & 6446 & 6497 & -51 & 2126 & 2136 & -10 \\
\hline 0.007 & -0.965 & 0.261 & 6308 & 6349 & -42 & 2425 & 2434 & -9 \\
\hline 0.012 & -0.865 & 0.501 & 5920 & 5965 & -46 & 3003 & 3037 & -34 \\
\hline 0.018 & -0.707 & 0.708 & 5521 & 5570 & -49 & 3422 & 3438 & -16 \\
\hline 0.022 & -0.500 & 0.866 & 5524 & 5555 & -30 & 3150 & 3163 & -14 \\
\hline 0.024 & -0.259 & 0.966 & 5757 & 5764 & -6 & 2465 & 2497 & -33 \\
\hline 0.022 & 0.000 & 1.000 & 5880 & 5862 & 18 & 2146 & 2136 & 10 \\
\hline 0.017 & 0.259 & 0.966 & 5772 & 5763 & 9 & 2540 & 2498 & 42 \\
\hline 0.008 & 0.500 & 0.866 & 5545 & 5554 & -9 & 3218 & 3169 & 49 \\
\hline-0.003 & 0.708 & 0.706 & 5612 & 5572 & 41 & 3451 & 3437 & 14 \\
\hline-0.013 & 0.867 & 0.499 & 6020 & 5971 & 49 & 2999 & 3030 & -31 \\
\hline-0.021 & 0.966 & 0.256 & 6400 & 6354 & 46 & 2429 & 2425 & 4 \\
\hline-0.025 & 1.000 & -0.003 & 6563 & 6497 & 67 & 2164 & 2137 & 27 \\
\hline-0.008 & 1.000 & 0.006 & 6562 & 6497 & 64 & 2166 & 2136 & 29 \\
\hline-0.007 & 0.964 & 0.265 & 6393 & 6345 & 49 & 2471 & 2443 & 28 \\
\hline-0.009 & 0.862 & 0.506 & 6004 & 5954 & 49 & 3053 & 3050 & 2 \\
\hline-0.012 & 0.701 & 0.713 & 5596 & 5563 & 33 & 3462 & 3441 & 21 \\
\hline-0.014 & 0.492 & 0.870 & 5582 & 5560 & 22 & 3163 & 3148 & 15 \\
\hline-0.013 & 0.250 & 0.968 & 5774 & 5770 & 4 & 2469 & 2475 & -6 \\
\hline-0.01 & -0.010 & 1.000 & 5872 & 5862 & 10 & 2140 & 2137 & 3 \\
\hline-0.003 & -0.268 & 0.964 & 5732 & 5757 & -25 & 2541 & 2520 & 20 \\
\hline 0.005 & -0.508 & 0.862 & 5509 & 5548 & -39 & 3193 & 3188 & 5 \\
\hline 0.015 & -0.713 & 0.701 & 5527 & 5579 & -52 & 3412 & 3433 & -22 \\
\hline 0.023 & -0.870 & 0.493 & 5954 & 5981 & -27 & 2956 & 3017 & -61 \\
\hline 0.028 & -0.967 & 0.252 & 6309 & 6359 & -50 & 2372 & 2416 & -44 \\
\hline 0.029 & -1.000 & -0.006 & 6433 & 6497 & -64 & 2126 & 2138 & -11 \\
\hline 0.029 & -0.999 & 0.034 & 6524 & 6494 & 30 & 2713 & 2703 & 10 \\
\hline-0.228 & -0.973 & 0.041 & 6470 & 6445 & 25 & 2667 & 2658 & 9 \\
\hline-0.469 & -0.882 & 0.047 & 6306 & 6276 & 30 & 2543 & 2541 & 2 \\
\hline-0.68 & -0.732 & 0.049 & 6028 & 5992 & 36 & 2418 & 2396 & 23 \\
\hline-0.845 & -0.533 & 0.048 & 5651 & 5623 & 29 & 2427 & 2409 & 18 \\
\hline-0.954 & -0.298 & 0.045 & 5288 & 5250 & 38 & 2575 & 2566 & 9 \\
\hline-0.998 & -0.042 & 0.040 & 5055 & 5042 & 13 & 2694 & 2699 & -5 \\
\hline-0.975 & 0.218 & 0.033 & 5179 & 5155 & 24 & 2617 & 2624 & -7 \\
\hline-0.886 & 0.464 & 0.025 & 5534 & 5502 & 32 & 2449 & 2449 & -1 \\
\hline-0.735 & 0.678 & 0.015 & 5871 & 5891 & -20 & 2387 & 2387 & 0 \\
\hline-0.533 & 0.846 & 0.005 & 6161 & 6211 & -50 & 2467 & 2481 & -14 \\
\hline-0.294 & 0.956 & -0.005 & 6400 & 6417 & -17 & 2618 & 2626 & -8 \\
\hline-0.033 & 0.999 & -0.014 & 6488 & 6495 & -8 & 2701 & 2702 & -1 \\
\hline-0.043 & 0.998 & -0.036 & 6471 & 6492 & -21 & 2692 & 2703 & -11 \\
\hline-0.303 & 0.953 & -0.025 & 6364 & 6410 & -46 & 2600 & 2622 & -22 \\
\hline-0.541 & 0.841 & -0.013 & 6142 & 6200 & -58 & 2448 & 2474 & -26 \\
\hline-0.742 & 0.671 & -0.001 & 5860 & 5878 & -18 & 2389 & 2387 & 2 \\
\hline-0.89 & 0.455 & 0.011 & 5493 & 5488 & 6 & 2465 & 2455 & 9 \\
\hline-0.978 & 0.209 & 0.021 & 5157 & 5145 & 12 & 2633 & 2630 & 3 \\
\hline-0.998 & -0.051 & 0.029 & 5066 & 5042 & 24 & 2690 & 2698 & -8 \\
\hline-0.951 & -0.306 & 0.034 & 5309 & 5261 & 48 & 2549 & 2561 & -12 \\
\hline-0.84 & -0.541 & 0.036 & 5691 & 5637 & 54 & 2419 & 2407 & 12 \\
\hline-0.674 & -0.738 & 0.035 & 5971 & 6005 & -34 & 2401 & 2401 & 0 \\
\hline-0.462 & -0.886 & 0.031 & 6287 & 6286 & 1 & 2541 & 2534 & 7 \\
\hline-0.22 & -0.975 & 0.024 & 6466 & 6451 & 14 & 2663 & 2660 & 3 \\
\hline 0.037 & -0.999 & 0.016 & 6512 & 6495 & 17 & 2708 & 2702 & 5 \\
\hline
\end{tabular}


Table 2. Direction of maximum and minimum $V_{P}$ and $V_{S}$.

\begin{tabular}{lcccc}
\hline & Vel (km/s) & \multicolumn{3}{c}{ Phonon Direction Cosines } \\
\hline Max $V_{P}$ & 6.497 & 0 & 1 & 0 \\
Min $V_{P}$ & 5.033 & 1 & 0 & 0 \\
Max V & 3.446 & 0 & -0.682 & 0.731 \\
Min $V_{S}$ & 2.136 & 0 & 1 & 0 \\
\hline
\end{tabular}

Using the inversion method of Brown [15], we obtained virtually identical results for the $C_{\mathrm{ij}}$ and their $1 \sigma$ uncertainties. Table 3 shows the resulting $C_{i j}$ values for hemimorphite. We note the large differences among the moduli $C_{11}, C_{22}$, and $C_{33}$, with $C_{11} 40 \%$ smaller than $C_{22}$, are a result of the large acoustic anisotropy of hemimorphite.

Table 3. Single-crystal elastic moduli of hemimorphite (GPa).

\begin{tabular}{ccccccccc}
\hline $\mathrm{C}_{\mathbf{1 1}}$ & $\mathrm{C}_{\mathbf{2 2}}$ & $\mathrm{C}_{33}$ & $\mathrm{C}_{44}$ & $\mathrm{C}_{55}$ & $\mathrm{C}_{66}$ & $\mathrm{C}_{\mathbf{1 2}}$ & $\mathrm{C}_{\mathbf{1 3}}$ & $\mathrm{C}_{23}$ \\
\hline $88.2(4)$ & $147.0(4)$ & $119.7(4)$ & $15.9(1)$ & $39.1(2)$ & $25.5(2)$ & $73.5(4)$ & $43.9(4)$ & $49.6(5)$ \\
\hline
\end{tabular}

From the single-crystal moduli, the Voigt, Reuss, and Hashin-Shtrikman bounds on the adiabatic bulk modulus $\mathrm{K}_{\mathrm{S}}$, and shear modulus $\mu$ of an isotropic aggregate were calculated, along with the Hill (Voigt-Reuss-Hill (VRH)) averages (Table 4). The Voigt and Reuss bounds on the bulk modulus and shear modulus differ by factors of $7 \%$ and $17 \%$, respectively. The differences are due to the moderately strong anisotropy for both longitudinal waves and shear waves. We note that the Hill average is within the range of the Hashin-Shtrikman bounds.

Table 4. Isotropic aggregate elastic properties of hemimorphite.

\begin{tabular}{ccccc}
\hline Aggregate Properties & Voigt & Reuss & $\begin{array}{c}\text { Hill (Voigt-Reuss-Hill } \\
\text { (VRH)) Averages }\end{array}$ & $\begin{array}{c}\text { Hashin-Shtrikman } \\
\text { Bounds }\end{array}$ \\
\hline Bulk modulus, $\mathrm{K}_{\mathrm{S}}, \mathrm{GPa}$ & $76.5(2)$ & $71.3(3)$ & $74(3)$ & $73.6(1)-74.8(1)$ \\
Shear modulus, $\mu, \mathrm{GPa}$ & $28.63(6)$ & $24.42(6)$ & $27(2)$ & $26.05(6)-27.04(6)$ \\
$\mathrm{V}_{\mathrm{P}}, \mathrm{km} / \mathrm{s}$ & $5.74(1)$ & $5.46(1)$ & $5.6(1)$ & $5.58(1)-5.64(1)$ \\
$\mathrm{V}_{\mathrm{S}}, \mathrm{km} / \mathrm{s}$ & $2.87(1)$ & $2.65(1)$ & $2.8(1)$ & $2.74(1)-2.79(1)$ \\
Density, $/ \mathrm{cm}^{3}$ & $3.48(3)$ & & & \\
\hline
\end{tabular}

From the values of $\mathrm{Ks}(\mathrm{VRH})$ and $\mu(\mathrm{VRH})$, the sound velocities appropriate to an isotropic polycrystalline aggregate were calculated to be $V_{P, a g g r}=\sqrt{ }\left(\frac{K+\frac{4}{3} \mu}{\rho}\right)=5.6(1) \mathrm{km} / \mathrm{s} ; V_{S, \text { aggr }}=\sqrt{ }\left(\frac{\mu}{\rho}\right)=$ $2.8(1) \mathrm{km} / \mathrm{s}$ (Table 4). The longitudinal and shear velocity anisotropy are defined as $\left(\mathrm{V}_{\mathrm{P}}, \mathrm{maximum}-\right.$ $\mathrm{V}_{\mathrm{P}}$, minimum $) / \mathrm{V}_{\mathrm{P}},(\mathrm{VRH})=26 \%$ and $\left.\left(\mathrm{V}_{\mathrm{S}}, \mathrm{maximum}-\mathrm{V}_{\mathrm{S}}, \mathrm{minimum}\right) / \mathrm{V}_{\mathrm{S}},(\mathrm{VRH})=47 \%\right)$, respectively.

Seryotkin et al. [16] studied the structural changes of hemimorphite at pressures up to 4.2 GPa by X-ray diffraction and the diamond-anvil cell. The purpose of their study was to search for a high-pressure phase transition, which they found near 2.5 GPa. We fitted their data on hemimorphite to a $2^{\text {nd }}$-order Birch Murnaghan equation of state and obtain $\mathrm{K}_{\mathrm{T}}=70(6) \mathrm{GPa}\left(\mathrm{K}_{\mathrm{T}}{ }^{\prime}\right.$ assumed to be 4$)$, in agreement with our result of $\mathrm{Ks}=74(3)$. Their experiments also show that the a-axis of hemimorphite is most compressible, while the b-axis is most rigid, in agreement with our result $C_{22}>C_{33}>C_{11}$. For the purpose of comparing our results and static compression results, we have ignored the difference between the adiabatic and isothermal bulk modulus, which is typically $\sim 1 \%$.

Interestingly, we note that our value of $\mathrm{Ks}$ for hemimorphite is in excellent agreement with the value of $\mathrm{K}_{\mathrm{T}}=72$ (2) GPa for bertrandite, $\mathrm{Be}_{4} \mathrm{Si}_{2} \mathrm{O}_{7}(\mathrm{OH})_{2}$, measured by Hazen and $\mathrm{Au}$ [17]. Bertrandite is topologically identical to hemimorphite, but differs chemically and does not contain molecular water in the large open cavities of the structure. The fact that bertrandite and hemimorphite have the same bulk modulus, despite having significant chemical differences, likely indicates a dominant influence of 
crystal-structural topology on the physical properties of these materials. However, it is also possible that the substitution of $\mathrm{Zn}$ for $\mathrm{Be}$, and the presence of $\mathrm{H}_{2} \mathrm{O}$ in hemimorphite, have opposite but equal effects on the bulk modulus that nearly cancel. There is some evidence to support this possibility. The $\mathrm{Zn}-\mathrm{O}$ bond is longer than the $\mathrm{Be}-\mathrm{O}$ bond and the bulk modulus of the $\mathrm{BeO}_{4}$ tetrahedron is significantly larger than that of the $\mathrm{ZnO}_{4}$ tetrahedron [18]. On the other hand, Cooper and Gibbs [11] found that upon dehydrating $\mathrm{H}_{2} \mathrm{O}$ from the structure, the large cavities contract. This may suggest that $\mathrm{H}_{2} \mathrm{O}$ provides support for the structure and stiffens it. It would be interesting to test this possibility on dehydrated hemimorphite, which would shed light on the effect of molecular water on this structure.

\section{Discussion}

The compressibility of minerals depends on the compressibility of the constituent cation polyhedra and their linkages to each other via angle-bending forces $[17,18]$. In their high-pressure X-ray structural study of bertrandite, $\mathrm{Be}_{4} \mathrm{Si}_{2} \mathrm{O}_{7}(\mathrm{OH})_{2}$, which is structurally identical to hemimorphite Hazen and $\mathrm{Au}[17]$, concluded that polyhedral rotation and angle bending were the main compression mechanisms, as opposed to compression of tetrahedra. This is supported by the fact that the bulk modulus of bertrandite, 70(3) GPa, is much smaller than the polyhedral bulk moduli of the $\mathrm{BeO}_{4}$ and $\mathrm{SiO}_{4}$ tetrahedra ( 200 GPa for both [17]). As noted above, our result for the bulk modulus of hemimorphite is identical to $\mathrm{K}_{\mathrm{T}}$ measured by Hazen and $\mathrm{Au}$ [17], providing additional support for this interpretation.

The $\mathrm{C}_{\mathrm{ij}}$ tensor of hemimorphite shows that strong anisotropy is a distinctive property of this mineral. We believe that this high degree of anisotropy is largely due to the topology of the hemimorphite crystal structure. $\mathrm{C}_{11}$ and $\mathrm{C}_{33}$ are the compressional moduli acting parallel to the corrugated sheets of tetrahedra. $C_{11}$ is a measure of the stiffness in the a direction, normal to the corrugations in the tetrahedral sheets (Figure 3). Strain in this direction can be accommodated by a high degree of angle bending of the corrugations in an accordion-like fashion, and with little or no strain of the tetrahedra themselves. Thus, the value of $\mathrm{C}_{11}$ is the lowest of the three compressional moduli.

The strongest elements in the hemimorphite crystal structure are the $\mathrm{Si}_{2} \mathrm{O}_{7}$ groups that bond across the apical oxygens in adjacent (010) layers. The structure cannot be compressed along [010] without some strain being accommodated by the $\mathrm{Si}$ tetrahedra, which are the strongest polyhedra [18]. The $\mathrm{Si}_{2} \mathrm{O}_{7}$ groups are essentially rigid pylons that stiffen the structure in the [010] direction. Thus, we attribute $\mathrm{C}_{22}$ being the largest longitudinal modulus of hemimorphite as being largely due to the $\mathrm{Si}_{2} \mathrm{O}_{7}$ groups. This situation is reminiscent of the olivine structure, in which $\mathrm{SiO}_{4}$ tetrahedra are contained in columns along the a direction, yielding $C_{11}$ as the largest longitudinal modulus [19].

$\mathrm{C}_{55}$ is the largest of the on-diagonal pure-shear moduli. The $\mathrm{C}_{55}$ modulus corresponds to shear within the (010) plane, parallel to the tetrahedral sheets. These corrugated sheets contain only 3-membered rings of $\mathrm{Zn}$ and $\mathrm{Si}$ tetrahedra. There is virtually no rotational freedom or angle-bending for 3-membered rings in response to a shear stress within their tetrahedral basal planes. Strain within the tetrahedral sheets must be accommodated by either shearing of the tetrahedra themselves, or perhaps the tilting of tetrahedra out of the basal plane. This gives the structure high shear rigidity within the plane of a tetrahedral sheet. In support of this interpretation, we look to mica, which has tetrahedral sheets within the a-b plane, parallel to (001). The shear modulus corresponding to this tetrahedral sheet is $\mathrm{C}_{66}=72 \mathrm{GPa}$ [20]. In comparison, the other shear moduli are far smaller, with $\mathrm{C}_{44}$ $=16.5 \mathrm{GPa}$ and $\mathrm{C}_{55}=19.5 \mathrm{GPa}$. In the cases of both hemimorphite and muscovite, the polyhedral topology, in particular tetrahedral sheets, dictates which of the pure shear moduli is largest. We suggest that the tetrahedral sheets in hemimorphite are less rigid than those in muscovite, for two reasons. Firstly, in hemimorphite, only $1 / 3$ of the tetrahedra are $\mathrm{SiO}_{4}$, the strongest tetrahedral unit [18], whereas in muscovite, all the tetrahedra are $\mathrm{SiO}_{4}$ in composition. Secondly, in muscovite the sheets are planar, whereas in hemimorphite the sheets are corrugated and exhibit some tilting of tetrahedra out of the (010) plane. Both the structural and chemical heterogeneity of hemimorphite make the rigidity of the tetrahedral sheets less than those in muscovite. 


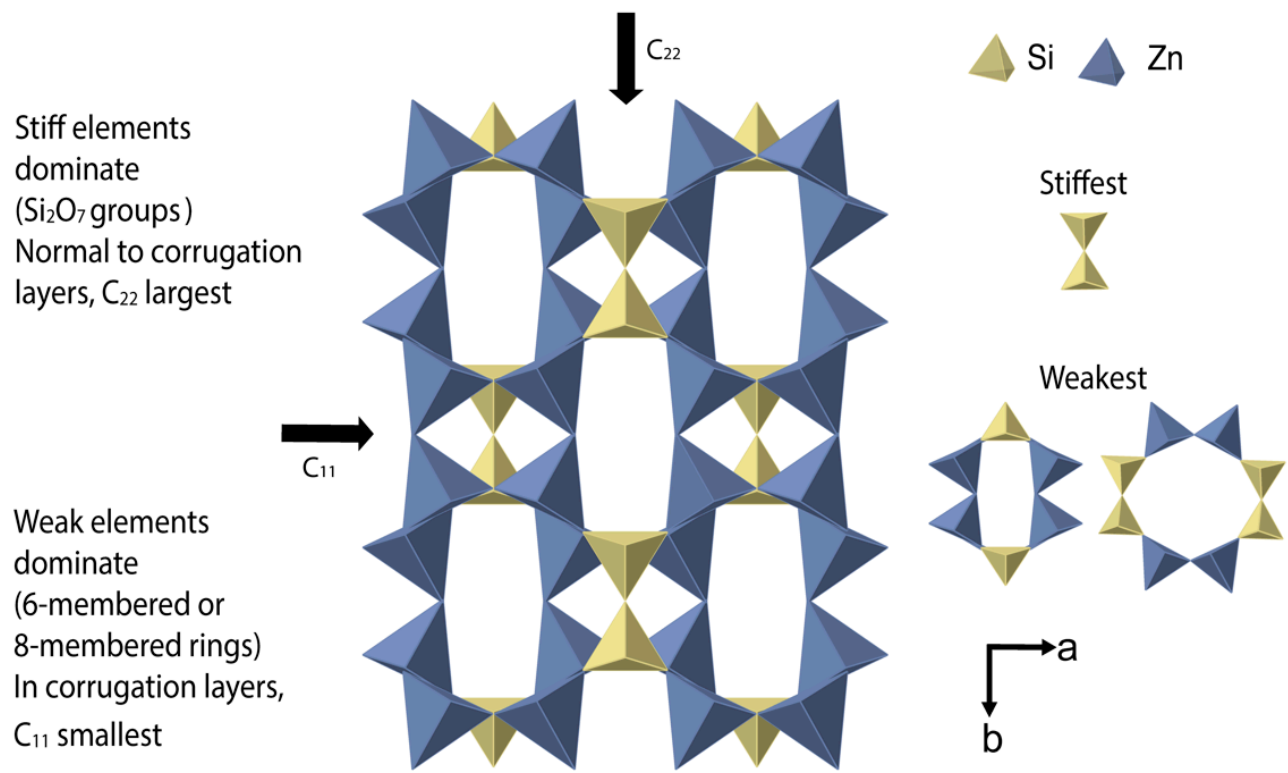

Figure 3. Schematic illustration of a polyhedral model of mineral elasticity. Hydrogens in molecular water and hydroxyls are omitted to emphasize linkages among Si and $\mathrm{Zn}$ tetrahedra into corrugated sheets of 3-membered rings parallel to (010), and the bridging between sheets. Stiffness parallel to [010], normal to the sheets, depends on the strongest structural element in this direction, which are $\mathrm{Si}_{2} \mathrm{O}_{7}$ and $\mathrm{Zn}_{2} \mathrm{O}_{6}(\mathrm{OH})_{2}$ groups that bridge the sheets along $\mathrm{b}$. Within the plane of the sheets, the moduli depend on the weakest structural elements [19]. $C_{11}$, measuring stiffness in the a direction, depends, in part, on the stiffness of relatively weak 6-membered and 8-membered rings, which can accommodate strain along [100].

\section{Conclusions}

The nine single-crystal elastic moduli of hemimorphite have been measured at ambient conditions. The relative magnitudes of the longitudinal elastic moduli, $\mathrm{C}_{22}>\mathrm{C}_{33}>\mathrm{C}_{11}$, can be qualitatively explained by the topology of the hemimorphite crystal structure. Strong $\mathrm{Si}_{2} \mathrm{O}_{7}$ groups greatly stiffen the structure along [010]. For the pure shear moduli, $C_{55}$ is the largest, due to the lack of rotational freedom of $\mathrm{Zn}$ and $\mathrm{Si}$ within three-membered rings in sheets parallel to (010). The elastic character of hemimorphite is largely determined by the topology of the crystal structure.

Author Contributions: Conceptualization, J.D.B.; methodology, J.D.B. and Y.L.; software, Y.L.; formal analysis, J.D.B. and Y.L.; investigation, formal analysis, J.D.B. and Y.L.; resources, J.D.B.; data curation, Y.L. and J.D.B.; writing—original draft preparation Y.L.; writing—review and editing, J.D.B.; visualization, Y.L.; supervision, J.D.B.; project administration, J.D.B.; funding acquisition, J.D.B. All authors have read and agreed to the published version of the manuscript.

Funding: This research was supported by the National Science Foundation, under grant EAR 16-20616.

Acknowledgments: The authors thank Jin S. Zhang for helpful suggestions and Paul Ginsberg for help with data analysis. We thank two anonymous reviewers, whose comments and suggestions improved the manuscript.

Conflicts of Interest: The authors declare no conflict of interest.

\section{References}

1. Wang, J.; Sinogeikin, S.V.; Inoue, T.; Bass, J.D. Elastic properties of hydrous ringwoodite. Am. Mineral. 2003, 88, 1608-1611. [CrossRef]

2. O'Neill, B.; Bass, J.D.; Rossman, G.R. Elastic properties of hydrogrossular garnet and implications for water in the upper mantle. J. Geophys. Res. Solid Earth 1993, 98, 20031-20037. [CrossRef]

3. Sinogeikin, S.V.; Bass, J.D. Single-crystal elastic properties of chondrodite: Implications for water in the upper mantle. Phys. Chem. Miner. 1999, 26, 297-303. [CrossRef] 
4. Hitzman, M.W.; Reynolds, N.A.; Sangster, D.F.; Allen, C.R.; Carman, C.E. Classification, genesis, and exploration guides for non-sulfide zinc deposits. Econ. Geol. Bull. Soc. 2003, 98, 685-714. [CrossRef]

5. Bissengaliyeva, M.R.; Bekturganov, N.S.; Gogol, D.B. Thermodynamic characteristics of a natural zinc silicate hemimorphite. J. Therm. Anal. Calorim. 2010, 101, 49-58. [CrossRef]

6. Kolesov, B. Raman investigation of $\mathrm{H}_{2} \mathrm{O}$ molecule and hydroxyl groups in the channels of hemimorphite. Am. Mineral. 2006, 91, 1355-1362. [CrossRef]

7. Taylor, H.F.W. The dehydration of hemimorphite. Am. Mineral. 1962, 47, 932-944.

8. Hill, R.J.; Gibbs, G.V.; Craig, J.R.; Ross, F.K.; Williams, J.M. A neutron-diffraction study of hemimorphite. Z. Kristallogr. 1977, 146, 241-259. [CrossRef]

9. McDonald, W.S.; Cruickshank, D.W.J. Refinement of the structure of hemimorphite. Z. Kristallogr. 1967, 124, 180-191. [CrossRef]

10. Takeuchi, Y.; Sasaki, S.; Joswig, W.; Fuess, H. X-ray and neutron diffraction study of hemimorphite. Proc. Jpn. Acad. 1978, 54, 577-582. [CrossRef]

11. Cooper, B.J.; Gibbs, G.V. The effect of heating and dehydration on the crystal structure of hemimorphite up to $600{ }^{\circ} \mathrm{C}$. Z. Kristallogr. 1981, 146, 241-259.

12. Whitfield, C.H.; Brody, E.M.; Bassett, W.A. Elastic moduli of $\mathrm{NaCl}$ by Brillouin scattering at high pressure in a diamond anvil cell. Rev. Sci. Instrum. 1976, 47, 942-947. [CrossRef]

13. Loudon, R.; Sandercock, J.R. Analysis of the light-scattering cross section for surface ripples on solids. J. Phys. C Solid State Phys. 1980, 13, 2609-2622. [CrossRef]

14. Weidner, D.J.; Carleton, H.R. Elasticity of coesite. J. Geophys. Res. 1977, 82, 1334-1346. [CrossRef]

15. Brown, J.M. Determination of elastic moduli from measured acoustic velocities. Ultrasonics 2018, 90, $23-31$. [CrossRef] [PubMed]

16. Seryotkin, Y.V.; Bakakin, V.V. Structural evolution of hemimorphite at high pressure up to 4.2 GPa. Phys. Chem. Miner. 2011, 38, 679-684. [CrossRef]

17. Hazen, R.M.; Au, A.Y. High-pressure crystal-chemistry of phenakite $\left(\mathrm{Be}_{2} \mathrm{SiO}_{4}\right)$ and bertrandite $\left(\mathrm{Be}_{4} \mathrm{Si}_{2} \mathrm{O}_{7}(\mathrm{OH})_{2}\right)$. Phys. Chem. Miner. 1986, 13, 69-78. [CrossRef]

18. Hazen, R.M.; Finger, L.W. Bulk modulus-volume relationship for cation-anion polyhedra. J. Geophys. Res. Solid Earth 1979, 84, 6723-6728. [CrossRef]

19. Bass, J.D.; Weidner, D.J.; Hamaya, N.; Ozima, M.; Akimoto, S. Elasticity of the olivine and spinel polymorphs of $\mathrm{Ni}_{2} \mathrm{SiO}_{4}$. Phys. Chem. Miner. 1984, 10, 261-272. [CrossRef]

20. Vaughan, M.T.; Guggenheim, S. Elasticity of muscovite and its relationship to crystal structure. J. Geophys. Res. Solid Earth 1986, 91, 4657-4664. [CrossRef] 